\title{
Contribution to the knowledge of the Proseriata (Platyhelminthes: Seriata) from eastern Australia. II. Genera Pseudomonocelis Meixner, 1943 and Acanthopseudomonocelis n. g.
}

\author{
Marco Curini-Galletti ${ }^{1} \&$ Lester Cannon ${ }^{2}$ \\ ${ }^{1}$ Istituto di Zoologia, Università di Sassari, via Muroni 25, I-07100 Sassari, Italy; ${ }^{2}$ Queensland Museum, \\ S. Brisbane, Queensland, 4101 Australia
}

Keywords: Platyhelminthes, Pseudomonocelis, Acanthopseudomonocelis, Australia, systematics, biogeography

\begin{abstract}
Two monocelid species with simplex copulatory bulbs and postpharyngeal ovaries have been found in E. Australia. One of them presents a combination of characters not found in any of the known genera of the Monocelididae, and the new genus Acanthopseudomonocelis is proposed for it. The new genus is characterized by the presence of four stylet-bearing accessory organs and by an internal vagina; it is related to Pseudomonocelis. The other species, Pseudomonocelis schockaerti n. sp., is characterized by a complex bursa-vagina system, and by a highly muscular penial organ and male antrum. It is closely related to $P$. pardii Schockaert \& Martens, 1987, from Somaliland. Two possibly additional species of the genus Pseudomonocelis, not found in a mature stage, are mentioned. The new findings considerably enlarge the known distribution of the genus Pseudomonocelis.
\end{abstract}

\section{Riassunto}

Due specie di Proseriata Monocelidae con bulbo copulatore di tipo simplex e ovari postfaringei sono stati rinvenuti in Australia orientale. Una di esse presenta una combinazione di caratteri non rinvenuta in alcuno dei generi noti della famiglia, e viene proposto per essa il genere Acanthopseudomonocelis gen. nov., caratterizzato dalla presenza di quattro organi accessori muniti di stiletto e di una vagina interna. Il nuovo genere è ritenuto essere filogeneticamente affine a Pseudomonocelis. La seconda specie (Pseudomonocelis schockaerti n. sp.) è caratterizzata dalla presenza di un complesso sistema bursa-vagina, e dall'organo copulatore e dall'atrio maschile rivestiti da spesse fibre muscolari. La specie è strettamente affine a $P$. pardii Schockaert \& Martens, 1987, nota per la Somalia. Vengono citate due ulteriori specie, non rinvenute allo stato adulto, e possibilmente attribuibili al genere Pseudomonocelis. Questi rinvenimenti allargono considerevolmente l'areale noto per il genere Pseudomonocelis.

\section{Introduction}

The genus Pseudomonocelis Meixner, 1943 (Platyhelminthes, Proseriata) is unique within the Monocelididae due to the presence of a copulatory organ of the simplex type, postpharyngeal ovaries, and absence of an accessory (prostatoid) organ. The revision of Schockaert \& Martens (1987) reported five species, from Europe and Somaliland. There is no general consensus, however, on the specific distinction of $P$. agilis (Schultze, 1851) and $P$. cetinae Meixner, 1943 (see Ax, 1959 and Sopott Ehlers, 1993).

A study of mesopsammic Proseriata from Eastern Australia yielded two new species with simplex copulatory bulb and postpharyngeal ovaries. One of them belongs to the genus Pseudomonocelis, while the other could not be placed in any monocelidid genus. Two additional species, not found in the adult stage, are mentioned here, in the light of the scanty knowledge of diversity and biogeography of the Australian Proseriata.

\section{Material and methods}

Specimens were collected in sandy habitats by scooping up the superficial layer of sediment. Extraction of the animals from the sediment was with $\mathrm{MgCl}_{2}$ decantation (see Martens, 1984). Preservation techniques routinely adopted for Proseriata were used (see Martens et al., 1989a). For microscopical analysis specimens were fixed in Bouin's fluid, embedded in $56^{\circ} \mathrm{C}$ paraplast and serial sagittal sections were cut at 2-4 $\mu \mathrm{m}$, stained with Mayer's haematoxylin and eosin and mounted in Depex. 
Pore indices, used in the species descriptions, give the relative distances between the mouth and the different genital pores (Karling, 1966): a, mouth-vagina; b, vagina-male pore; c, male pore-female pore.

Karyological techniques were as described by Curini-Galletti et al. (1989). Relative lengths (r.l. = length of chromosome $x$ $100 /$ total length of haploid genome) and centromeric indices (c.i. = length of short arm $\times 100 /$ length of entire chromosome) were obtained from measurements of camera lucida drawings of 5-10 metaphase plates for each species. Idiograms are based on karyometrical data presented in the karyotype formula: haploid genome absolute length in $\mu \mathrm{m}$, fundamental number, relative length and centromeric index of each chromosome; chromosome nomenclature between parentheses ( $m=$ metacentric; $s m=$ submetacentric; st = subtelocentric; $t=$ acrocentric). The fundamental number (NF) is derived according to Matthey (1949) and chromosome nomenclature follows Levan et al. (1964).

The type material is stored in the collections of the Queensland Museum, Brisbane.

\section{Abbreviations used in the figures}

a atrium
aao anterior accessory organ
ag atrial glands
am atrial musculature
aog accessory organ gland
b bursa
bb basal bulb
br brain
co copulatory bulb
cp common (male + vagina) pore
e pigmented eye-spots
eg eosinophilous gland
ep eversible penis
fd female duct
fg female glands
fp female pore
gl gut lumen
in intestine
iv internal vagina
m mouth
ma male antrum
mp male pore
ms muscle sheath
ob outer bursa
od oviduct
ov ovary
p pigment
pao posterior accessory organ
pe penis papilla
pg prostatoid glands
ph pharynx
phg pharyngeal glands

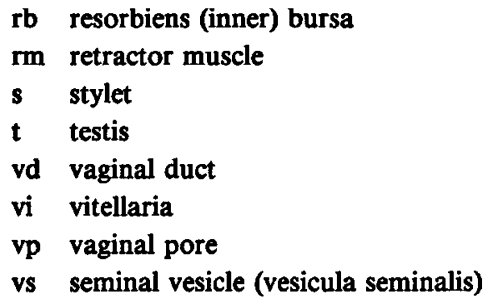

\section{Species descriptions}

Fam. Monocelididae

Gen. Pseudomonocelis Meixner, 1943

Pseudomonocelis schockaerti n. sp.

(Figs. 1, 4A, 5A-C)

Material studied. - Two specimens serially sectioned (holotype: G211672; paratype: G211673); ten specimens observed alive; eight specimens used for karyology.

Type locality. - E. Australia, Queensland, Caloundra, Shelly Beach, high intertidal pools; mixed sediment: coarse sand and shell grit with low amounts of silt (August/September 1993).

Etymology. - Named after Prof. Dr. E. Schockaert, for his contribution to the systematic knowledge of free-living Platyhelminthes and for his critical advice on the reconstruction of the anatomy of this species.

Description. - Relatively very large animals; sectioned specimens are about $2.5 \mathrm{~mm}$ long. Anterior end rounded, provided with numerous oily droplets. Posterior end rounded, with very numerous adhesive papillae. A brownish pigment band is present in front of the statocyst. Two pigmented eyespots are present lateral to the statocyst. The epidermis, with insunk nuclei, is ciliated except at the caudal tip. It is provided all over the body with numerous elongated rhabdites (about $15 \mu \mathrm{m}$ long). Cilia are 5-6 $\mu \mathrm{m}$ long; slightly longer ventrally than dorsally. Large glands, whose necks pierce the epithelium, are present ventrally, and, in the posterior area of the body, also dorsally; they are particularly numerous at the caudal tip. These glands are 20 to 
$40 \mu \mathrm{m}$ long, ovoid, with a flat nucleated lining and a granular eosinophilous content. The pharynx is nearly in the middle of the body. It is comparatively short and broad. Its external and luminal epithelia are ciliated; its most distal tip, where pharyngeal glands discharge, is unciliated. The luminal epithelium is also unciliated in a narrow proximal area, adjacent to the very short oesophagous (about 1/7 of the pharynx length).

Male genital organs: Numerous testes $(30-50)$ occur in two irregular rows in front of the pharynx. The copulatory bulb appears nearly globular, 120 $\mu \mathrm{m}$ long, $110 \mu \mathrm{m}$ wide. It consists of an ovoid seminal vesicle, surrounded by thick muscle layers (with inner circular and outer longitudinal muscles), and of a very muscular penis papilla. The seminal vesicle is lined by an epithelium which is rather thin proximally, where the nuclei are irregularly arranged in two layers. The luminal border of the epithelium is distinctly eosinophilous. Distally, the epithelium is high, presumably glandular, and internally coats the penis papilla. The nuclei of these prostatic glands lie mostly laterally to the bulb. The penis papilla is large, more than one third the length of the copulatory organ, and is broadly conical in shape. It is highly muscular, with circular fibres on both sides, and a few inner longitudinal muscles, apparently joining the longitudinal fibres enveloping the bulb. The male antrum is narrow and ciliated; it is entirely and homogeneously surrounded by a thick layer of retractor muscles. The antrum opens to the exterior through a male pore.

Female genital organs: Vitellaria extend from about the level of the first testes to behind the copulatory bulb. Two ovaries lie ventrolaterally behind the pharynx. They are enveloped by a thin cellular tunica propria. A very short common female duct was seen emerging posterodorsally from the ovaries; its place of insertion with the bursa could not be discerned. The vagina-bursa system is highly elaborated. The bursa has an inner part, whose lumen is surrounded mostly by thick, vacuolar walls, and which constitutes the resorbiens portion. Its lining becomes dorsally very thin and irregular, and connections with the gut lumen have been observed. This resorbiens bursa communicates posteriorly, through a wide septum, with an outer part which has thick, non-vacuolar walls lined with ciliated epithelium and bounded by an outer ring of circular muscles. In the sectioned animals, both portions of the bursa were filled with sperm. From the outer chamber of the bursa a long, posteriorly oriented, ciliated (cilia length: 7-8 $\mu \mathrm{m}$ ) vaginal duct originates. This duct has thick muscular walls, particularly in its proximal part, where numerous circular muscles are present. The common female duct is unciliated and runs from the posterodorsal part of the bursa to the female pore. Its actual connections with the bursa could not be seen. The female pore is surrounded by very numerous glands.

Pore ratio: $c>a>b$.

Karyology. - With 3 chromosomes in its haploid set. Karyotype formula: $10.2 \pm 0.6 \mu \mathrm{m} ; \mathrm{NF}=5$; chromosome $1: 37.37 \pm 2.03$; $45.67 \pm 2.10(\mathrm{~m})$; chromosome $2: 37.09 \pm 1.69 ; 40.52 \pm 1.51$ $(\mathrm{m})$; chromosome $3: 25.52 \pm 1.04 ; 10.22 \pm 3.46(\mathrm{t})$. One specimen had chromosome 2 heteromorphic due to a pericentric inversion affecting one of the chromosomes of the pair, which resulted in an acrocentric chromosome (Fig. 5C).

\section{Discussion}

The new species belongs to the genus Pseudomonocelis Meixner, 1943 due to the postpharyngeal position of the ovaries, the copulatory bulb of the simplex type (sensu Karling, 1956), and the absence of an accessory (prostatoid) organ. Among the few known species of the genus (see Schockaert \& Martens, 1987 for a revision) it appears to be most similiar to $P$. pardii Schockaert \& Martens, 1987 from Somaliland. The two species have in fact practically identical pigmentation, number and arrangement of testes, general topography of the genital organs, and pore ratio. However, they differ in several characters which justify the status of $\boldsymbol{P}$. schockaerti as a distinct species:

(1) $P$. pardii has epithelial cilia densely packed and short $(2-3 \mu \mathrm{m})$, whereas cilia in $P$. schockaerti are longer $(5-6 \mu \mathrm{m})$.

(2) In $P$. pardii the copulatory bulb is about 95 $\mu \mathrm{m}$ wide, with the muscular wall much broader distally than proximally, forming a thick broad penis papilla which is not clearly set off. In $P$. schockaerti the copulatory bulb is slightly larger $(110 \mu \mathrm{m}$ wide), 


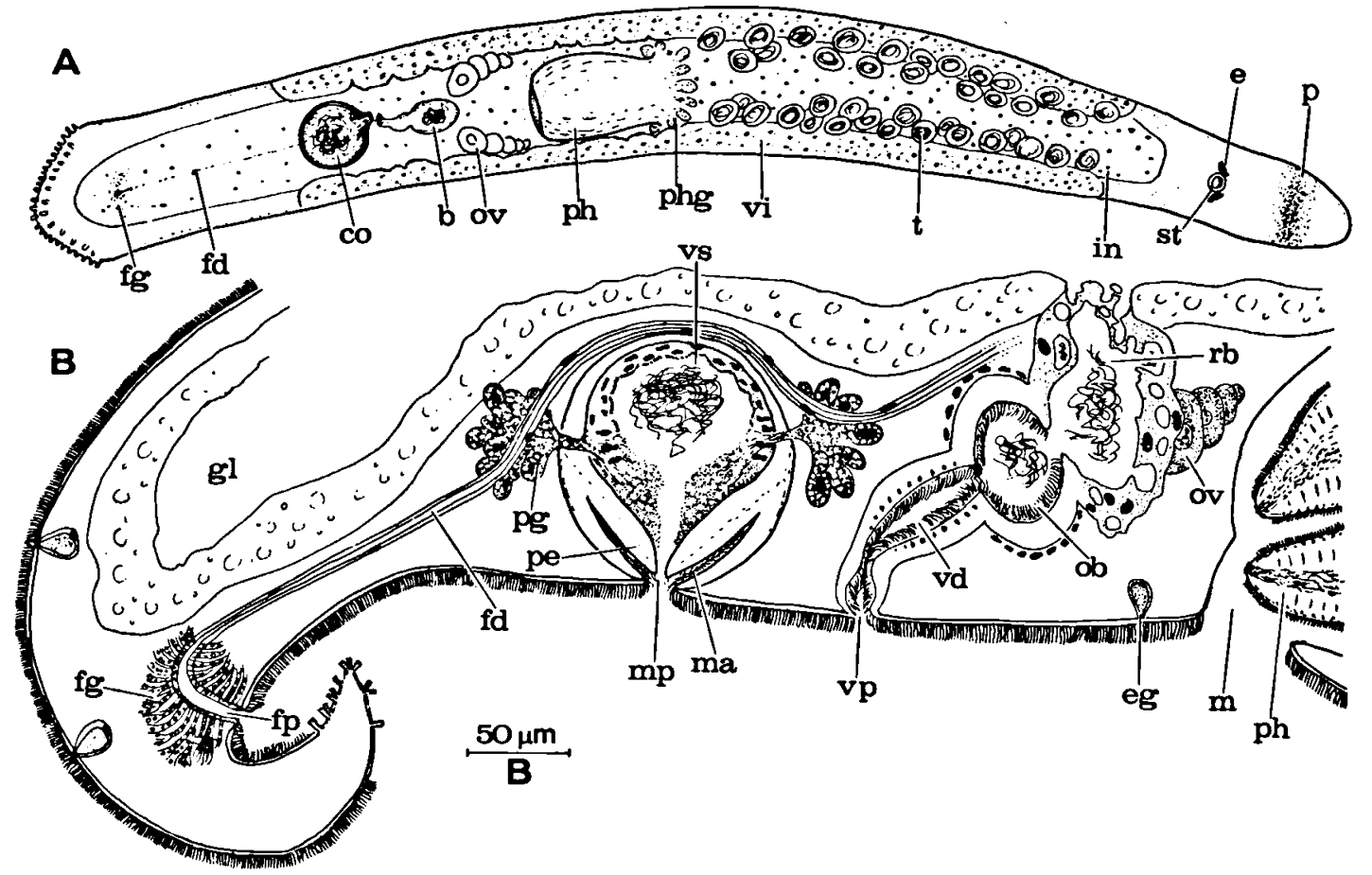

Fig. 1. Pseudomonocelis schockaerti n. sp.: A, general organization of a live animal; B, reconstruction of the genital organs from sagittal sections.

with the distal muscular wall not broadened and forming a well-defined, conical penis papilla. The differences are already appreciable in semi-squashed living specimens (cf. Fig. 1A in present paper with Schockaert \& Martens, 1987: 105, fig. 1B).

(3) The male antrum is longer than wide in $P$. pardii. In this species, most retractor muscles of the copulatory bulb are attached only to the proximal part of the antrum. On the contrary, the antrum is much wider than long in $P$. schockaerti, and retractor muscles are attached to the whole antrum, forming an evenly developed thick muscular wall around it. The antrum is ciliated in $P$. schockaerti, unciliated in $P$. pardii.

(4) Schockaert \& Martens (1987) interpreted the bursal system of $\boldsymbol{P}$. pardii as composed of two portions: a muscular "horizontal canal", connected ventrally to the vaginal duct, and a true bursa, of the resorbiens type, posteriorly connected to the canal. This basic architecture is very similar to the bursa-vagina system found in $\boldsymbol{P}$. schockaerti. However, in the last-mentioned species the "horizontal canal" is a veritable bursa, large and nearly spherical. Both of the two sectioned specimens had, in fact, sperm in it, as well as in the resorbiens portion. On the contrary, sperm has not been observed in the "horizonal canal" of $\boldsymbol{P}$. pardii (see Schockaert \& Martens, 1987: 106, fig. 2); in that species the canal is indeed much more elongate and narrower than the "outer bursa" of $P$. schockaerti. Furthermore, the "outer bursa" and the vaginal duct are ciliated in $P$. schockaerti; in contrast, the female system is wholly unciliated in $P$. pardii.

No other species of the genus Pseudomonocelis has a comparable muscular antrum or bursa-vagina system, nor is the structure known from the related genus Monocelis Ehrenberg, 1831. These characters are here considered as synapomorphies shared by $\boldsymbol{P}$. pardii and $P$. schockaerti. The finding of closely related species of interstitial organisms in $\mathbf{E}$. Africa and E. Australia has potential biogeographical interest. Unfortunately, the biogeography of mesopsammic platyhelminthes is severely biased by paucity of reports. At present, two alternative 
hypotheses can be formulated: (1) a "tropical" origin, i.e., the two species share a common ancestor, distributed in (parts of) the Indo-Pacific; (2) a "southern" origin, i.e., the common ancestor had a Gondwanian distribution, and speciation occurred after the break-up of Gondwana. The finding of related species of the complex in other areas, derived or not from Gondwana, would be crucial in favouring one or the other of the hypotheses. In any case, the finding of $P$. schockaerti in E. Australia considerably enlarges the known distribution of the genus, so far only known from Europe and Somaliland.

\section{Pseudomonocelis sp. A.}

(Figs. 4B, 5D)

Locality. - Queensland, Stradbroke Is., Myora Reef; high intertidal, mixed sediment: coral and shell rubble with silt (July 1993).

Material studied and description. - One juvenile specimen, with two pigmented eyespots lateral to the statocyst and a brown pigment band in front of the statocyst. The epidermis was provided all over the body with numerous elongated rhabdites, and large ovoidal glands, similar in shape and arrangement to the previous species. Pharynx short and broad, nearly terminal. The specimen was not sexually mature.

Karyology. - With 3 chromosomes in its haploid set. Karyotype formula: $11.9 \pm 0.2 \mu \mathrm{m} ; \mathrm{NF}=6$; chromosome 1: $40.01 \pm 0.97$; $48.05 \pm 0.01(\mathrm{~m})$; chromosome $2: 34.30 \pm 0.62 ; 44.19 \pm 2.73$ (m); chromosome 3: $25.69 \pm 1.58 ; 35.74 \pm 3.32(\mathrm{sm})$.

Remarks. - The specimen was identical to juvenile $P$. schockaerti. The karyotype, however, is sufficiently different to warrant a distinct species status. In particular, chromosomes 1 and 2 are nearly identical in size in $P$. schockaerti, whereas they are distinctly different in Pseudomonocelis sp. A. Chromosome 3 is acrocentric in $P$. schockaerti, submetacentric with a very high index in Pseudomonocelis sp. A. Genome length is also different. The magnitude of karyotype differentiation among the two species is comparable to that found among electrophoretically and reproductively tested sibling species of the Pseudomonocelis ophiocephala (Schmidt, 1861) complex (Curini-Galletti, in prep.). Whether or not a sibling complex of brown-pigmented Pseudomonocelis is also present in Australian waters remains to be studied; at least juveniles of the two species appear morphologically indistinguishable.

\section{Pseudomonocelis ? sp. B}

(Figs. 2F, 4C, 5E)

Locality. - Queensland, Heron Is., in front of the heliport, about $1 \mathrm{~m}$ deep in silty sediments (October 1993).

Material studied and description. - Animals very small (less than $1 \mathrm{~mm}$ long in living extended conditions), slender and agile, with a bright pink (in reflected light) or brownish (in transmitted light) pigment band in front of the statocyst, and two pigmented eyespots lateral to the statocyst. Large rhabdites present all over the body, and an elongated pharynx in the middle of the body.

All six specimens studied were immature in the female line. One specimen mature in the male line had three testes, and a very small copulatory organ, with an apparently backwardly oriented, elongated penis papilla.

Karyology. - With 3 chromosomes in its haploid set. Karyotype formula: $10.7 \pm 0.8 \mu \mathrm{m} ; \mathrm{NF}=5$; chromosome $1: 37.87 \pm 1.78$; $45.85 \pm 2.12(\mathrm{~m})$; chromosome $2: 33.57 \pm 1.98 ; 45.84 \pm 2.71$ (m); chromosome 3: $28.55 \pm 1.56 ; 20.99 \pm 2.34$ (st).

Remarks. - Though relatively common in the harbour of Heron Is., none of the specimens found was sufficiently mature to allow a formal description, and placement in the genus Pseudomonocelis, suggested by pharynx position, has to be considered as provisional. However, the species is clearly distinct from any other monocelidid species known, due to its peculiar pigmentation and karyotype.

\section{Acanthopseudomonocelis gen. nov.}

Diagnosis. - Monocelididae with an internal vagina and a common atrium. With four lateral stylet- 
bearing accessory organs, symmetrically arranged between the common pore and the female pore.

Type species (by monotypy). - A. mirabilis n. sp.

Etymology. - The genus name is coined on the generic taxon Pseudomonocelis and refers to the presence of stylet-bearing accessory organs (from the Greek acanthòs = spine); it is feminine.

\section{Acanthopseudomonocelis mirabilis $\mathbf{n}$. sp.}

(Figs. 2A-E, 3, 4D, 5F-H)

Material studied. - Five specimens serially sectioned (holotype: G211674; paratypes: G211675-8); two specimens prepared as whole mounts (G211679-80); four specimens used for karyology.

Type locality. - E. Australia, Queensland, Heron Is., in front of the heliport, about $1.5 \mathrm{~m}$ deep in mixed sediment (very silty coarse sand and gravel) (October 1993).

Etymology. - The specific epithet mirabilis (from the Latin, meaning "admirable") refers to the striking features of the species (arrangement of stylets, pigmentation, etc.).

Description. - Sectioned specimens are about $1 \mathrm{~mm}$ long. Anterior end rounded, provided with oily droplets. Several irregular, transversally elongated pigment spots are present in front of the statocyst. They are very variable in number and shape among the specimens examined, and vary from four, more or less parallel, narrow bands to numerous irregular dots, variously arranged and fused. These pigment dots are grey in transmitted light, shiny white in reflected light. Lateral to the statocyst, two pigmented eyespots are present. Posterior to the eyes, over the brain area, numerous small pigment dots are present, similar in colour to the eyespot pigment. The central tissue of the brain (neuropilem) is surrounded by numerous nuclei; anteriorly, it abuts the statocyst. Posterior end rounded, with adhesive glands. The epidermis, with insunk nuclei, is ciliated except at the caudal tip. All over the body the epidermis is provided with numerous elongated rhabdites (about 5-10 $\mu \mathrm{m}$ long), which are more densely arranged in the cephalic and caudal regions. Cilia range 3.5-4 $\mu \mathrm{m}$ in length; they are slightly longer ventrally than dorsally. The pharynx is situated in the second half of the body. Its epithelium is devoid of cilia at its most distal tip (a very small area where pharyngeal glands discharge) and on its inner proximal third. In the innermost proximal quarter, the luminal epithelium is high and devoid of cilia (oesophagus). Beneath both outer and inner epithelia, an outer layer of longitudinal muscle fibres and an inner layer of circular muscles are present. The circular musculature on the outer side of the pharynx attenuates distally.

Male genital organs: Numerous testes (about 30) in front of the pharynx. The copulatory organ, of the simplex typc, is nearly globular, about $50 \mu \mathrm{m}$ wide, $33 \mu \mathrm{m}$ high. Its muscular wall is irregular in thickness (varying 4.5-8 $\mu \mathrm{m}$ ) and is formed by inner circular and outer longitudinal muscles. The bulb contains an ovoidal seminal vesicle, lined with a thin nucleated epithelium. Distally, this epithelium forms the prostatic glands, whose nuclei lie outside the bulb. The distal portion of the bulb is inverted, forming a long eversible penis, which has very thin and probably unciliated walls. The male copulatory organ protrudes into the common atrium (see also below), which is ciliated. The atrium is asymmetrical and widens mostly anteriorly, where the internal vagina is present. The atrium is surrounded by thick muscle layers, particularly in its distal part. These muscle layers mostly consist of strongly developed retractor muscles, attached to the bulbus. The atrium opens to the outside through a wide pore. Numerous elongated atrial glands are present, whose outlets are just proximal to the pore.

Accessory (prostatoid) organs: Most specimens (nine out of eleven) had four symmetrically arranged accessory organs. There are two anterior accessory organs, located lateral to the male copulatory organ, and two posterior ones, located between the copulatory bulb and the female pore. Two specimens, which might have not been fully mature, had only the posterior pair. The accessory organs consist of a basal bulb with a stylet. The bulb (larger in the posterior pair) is surrounded by a thick muscular wall, and contains a granular 


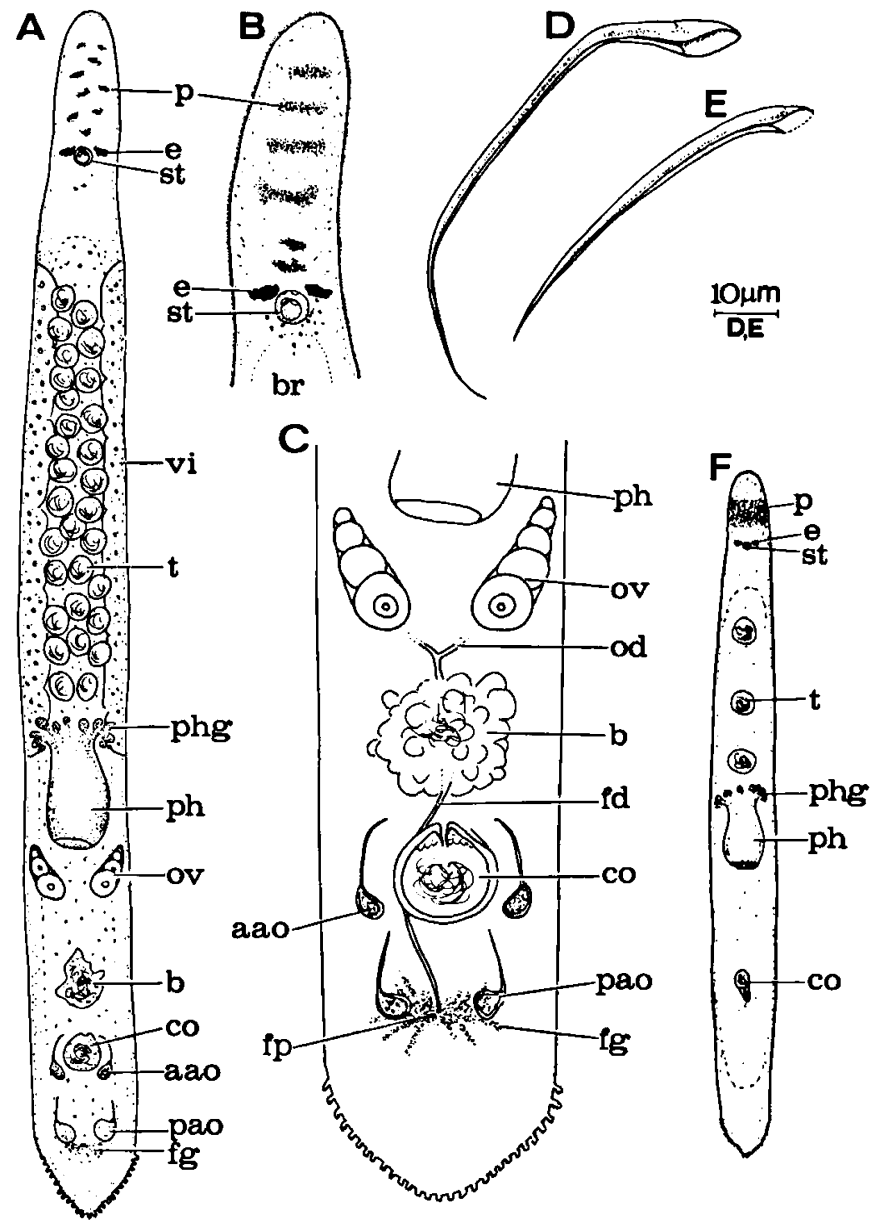

Fig. 2. A-E, Acanthopseudomonocelis mirabilis g. et sp. n.: A, general organization of a live animal; B, details of the cephalic region; C, general organization of the genital organs from live animals; D, anterior accessory stylet; E, posterior accessory stylet.

F, Pseudomonocelis? sp. B: general organization of a live animal.

eosinophilic secretion, produced by cells whose bodies lie outside the bulb. The stylets are guttershaped and extremely elongate: in the anterior pair they are longer (about $90 \mu \mathrm{m}$ in length) and curved at the top; in the posterior organs they are shorter (about $60 \mu \mathrm{m}$ ) and straighter. The stylet bases lie within the bulb. The stylets are enclosed for most of their length by a closely fitting muscular sheath which attenuates distally, disappearing in the most distal portion. Neither in living specimens nor in sections could the presence of accessory organ pores be ascertained. The stylets end in an area of fibrous tissue, leading to a tiny interruption of the basal lamina. The anterior pair ends just anteriorly of the atrial pore; the posterior ones almost midway between the atrial pore and the female pore.

Female genital organs: Two ovaries ventrolaterally posterior to the pharynx. They consist of up to seven oocytes in one row, with the oldest ones placed posteriorly, surrounded by a thin cellular tunica propria. Vitellaria extend from just in front of the first testes to the root of the pharynx. The two oviducts are very short and fuse in front of a large bursa. This bursa, that is of the resorbiens type, is lined with a high nucleated epithelium, and, particularly in its anterior half, consists of very numerous interconnected vacuoles, resulting in a somewhat spongy structure. Some of the vacuoles, as well as the posterior larger cavity, contain sperm. The bursa is connected to the atrium with a very 

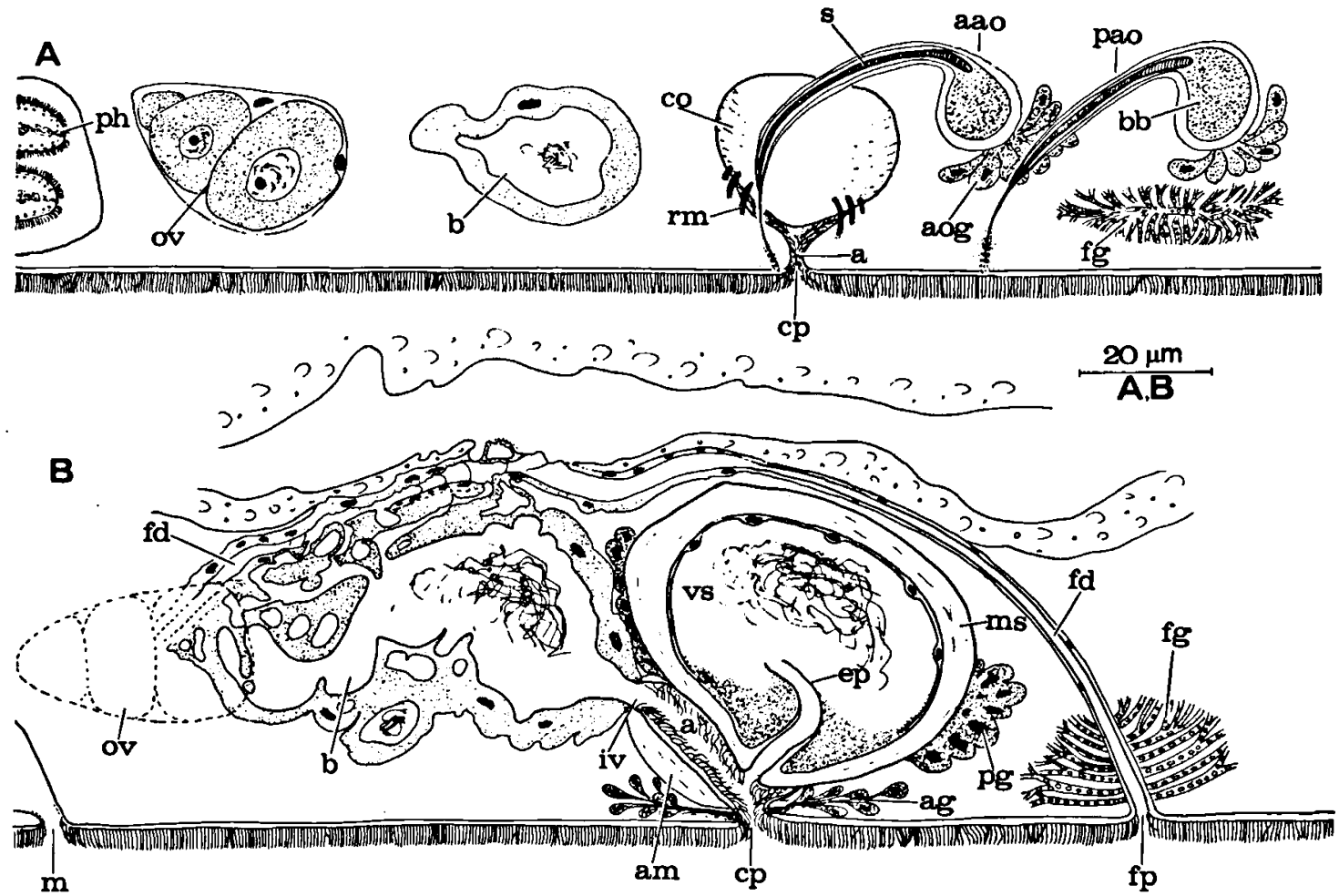

Fig. 3. Acanthopseudomonocelis mirabilis g. et sp. n., reconstruction of the genital organs from sagittal sections: A, mediolateral plane; B, median plane.

short ventroposterior internal vagina. The common female duct is dorsal to the bursa, and, at least in the portion overlying the anterior half of the bursa, its walls are vacuolar and irregular, with numerous trabeculae and lacunae connecting the duct to the bursa vacuoles. Anteriorly, the duct could be followed till the level of the ovaries. In a few areas, the dorsal walls of the duct are in contact with the gut lumen, and, due to irregularity of the duct lining, connections are probably present. Posteriorly, the unciliated epithelium of the duct progressively becomes a normal, complete epithelial lining. The female duct is connected to the outside through the female pore, surrounded by female glands.

Pore ratio: $\mathbf{a}>>$ c.

Karyology. - With 2 chromosomes in its haploid set. Karyotype formula: $5.3 \pm 0.3 \mu \mathrm{m} ; \mathrm{NF}=4$; chromosome 1: $62.17 \pm 3.68$; $42.92 \pm 1.63(\mathrm{~m})$; chromosome $2: 37.83 \pm 3.68 ; 46.16 \pm 1.22$ (m).

\section{Discussion}

Recent nucleotide sequence data no longer support the traditional subdivision of the Monocelididae into the Minoninae Karling, 1978 (including genera with stylet-bearing accessory organ), and the Monocelidinae Midelburg, 1908 (without accessory organ). On the contrary, this approach revealed that (1) species with a simplex type of copulatory bulb (cf. Karling, 1956) are closely related, and (2) the presence of an accessory organ has to be considered as a plesiomorphic feature for the Monocelididae (Litvaitis et al., in prep.).

Stylet-bearing accessory organs are found in the genera Peraclistus Steinbock, 1932, Ectocotyla Hyman, 1944, Minona Marcus, 1946, Preminona Karling, 1966, Duplominona Karling, 1966, Pseudominona Karling, 1978, and Duploperaclistus Martens, 1983. Among them, a simplex type of copulatory bulb is found only in the genera Pera- 


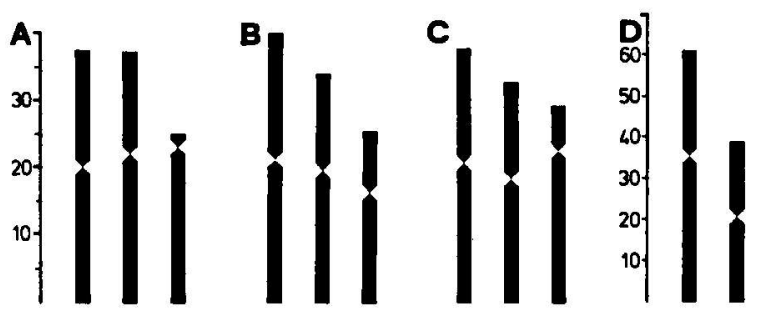

Fig. 4. Idiograms (based on relative lengths) representing the haploid sets of Pseudomonocelis schockaerti sp. n. (A), Pseudomonocelis sp. A (B); Pseudomonocelis ? sp. B (C); Acanthopseudomonocelis mirabilis $\mathrm{g}$. et $\mathrm{sp}$. $\mathrm{n}$. (D).

clistus, Minona, and Ectocotyla. Only the latter genus comprises species with postpharyngeal ovaries. However, Ectocotyla species have the pharynx just behind the brain, with inverted muscular fibres (i.e., with an outer circular muscle layer and an inner longitudinal muscle layer) compared to all other Monocelididae, a postpenial external vagina, and 6 chromosomes in their haploid set (Fleming \& Burt, 1978). In all the genera mentioned above only one accessory organ is present, located medially, generally posterior to the copulatory bulb, and provided with a clear external pore (sometimes secondarily fused with other genital pores). An exception is formed by Minona gemella Ax \& Sopott-Ehlers, 1985, which has two accessory organs (one in front and one behind the copulatory organ). The stylet is usually short and pen-nib shaped. Out of the numerous species of the group, only Minona hastata Martens \& Curini-Galletti, 1989 and M. stimula Ax \& Ax, 1977 have a needlelike stylet, comparable to the new species. The accessory organs of the new species, however, present clearly derived characters, such as their number (four), lateral position, and absence of an external pore. In particular, this latter feature might even raise questions whether these structures are indeed homologous to the accessory organs found in the other stylet-bearing species. Number and position of the accessory organs, shape of stylets, and absence of an external pore are apomorphies for the new species.

Within the Monocelididae, postpharyngeal ovaries, medioposterior pharynx with circular muscle fibres underlying longitudinal fibres, and simplex

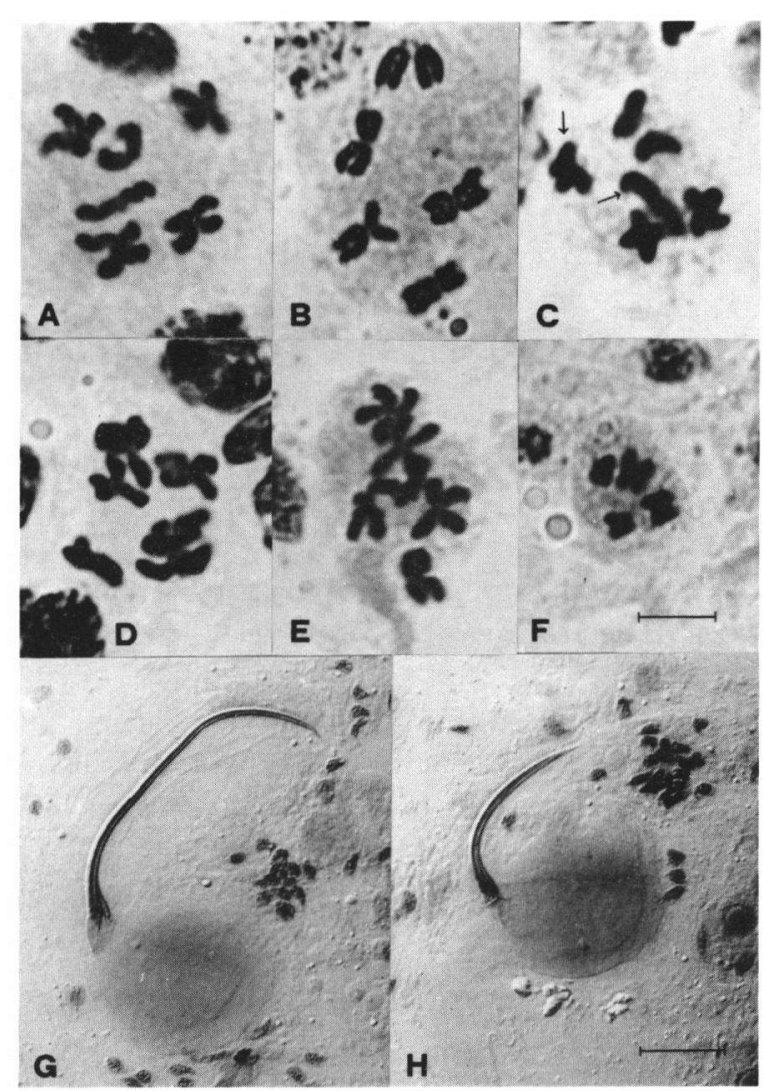

Fig. 5. A-F: spermatogonial mitoses. A-C, Pseudomonocelis schockaerti $\mathrm{n}$. sp. (C = anomalous specimen (see text for explanation); arrows point to heteromorphic pair 2); D, Pseudomonocelis sp. A; E, Pseudomonocelis ? sp. B; F, Acanthopseudomonocelis mirabilis g. et sp. $\mathrm{n}$.; scale bar $\mathrm{A}-\mathrm{F}=5 \mu \mathrm{m}$.

G-H: accessory (prostatoid) organs of $A$. mirabilis g. et sp. $n$. $\mathrm{G}$, anterior accessory organ; $\mathrm{H}$, posterior accessory organ; scale bar $\mathrm{G}-\mathrm{H}=20 \mu \mathrm{m}$.

copulatory bulb are only found in the genus Pseudomonocelis. However, this genus contains species without an accessory stylet, and with an external vagina (cf. Schockaert \& Martens, 1987). Furthermore, all known Pseudomonocelis species have a karyotype with three chromosomes in their haploid set and a large haploid genome length (present paper, and unpublished data). The new species has $\mathbf{n}=2$, and a very small haploid genome length, about half the value found in Pseudomonocelis species. The reduction from the basic number for the Monocelididae $\mathrm{n}=3$ (cf. Martens et al., 1989b) is due to a Robertsonian mechanism of chromosome 
fusion and is an apomorphy for the new species. Additional species with a simplex copulatory bulb that are karyologically known belong to the genera Monocelis and Minona. They mostly present large (about $10 \mu \mathrm{m}$ ) genome length (see Curini-Galletti, 1991; Curini-Galletti \& Cannon, in press; Martens \& Curini-Galletti, 1987). The small genome length value as found in the new species might thus be another apomorphy for it.

The combination of derived characters present in the new species (vagina interna, four stylet-bearing accessory organs lacking an external pore, two chromosomes in the haploid set, small haploid genome length) are not found in any other monocelidid genus. The erection of the new genus is therefore justified.

Based on the position of the ovaries and the pharynx, and on the bulb structure, the new genus appears to be related to Pseudomonocelis.

\section{Acknowledgements}

Dr. Ian Lawn and the staff of the Heron Is. Research Station are gratefully acknowledged for providing hospitality and research facilities. Zeinab Khalil and Giuseppe Delitala are thanked for their skilful technical assistance.

\section{References}

Ax, P., 1959. Zur Systematik, Ökologie und Tiergeographie der Turbellarienfauna in den ponto-kaspischen Brackwassermeeren. Zool. Jahrb. (Syst.), 87: 43-184.

Curini-Galletti, M., 1991. Monocelididae (Platyhelminthes: Proseriata) from Puerto Rico. I. Genera Minona and Monocelis. Proc. biol. Soc. Wash., 104: 229-240.

Curini-Galletti, M. \& L. Cannon, in press. Contribution to the knowledge of the Proseriata (Platyhelminthes: Seriata) from eastern Australia: genus Monocelis Ehrenberg, 1831. J. nat. Hist.
Curini-Galletti, M., I. Puccinelli \& P.M. Martens, 1989. Karyometrical analysis of ten species of the subfamily Monocelidinae (Proseriata, Platyhelminthes) with remarks on the karyological evolution of the Monocelididae. Genetica, 78: 169-178.

Fleming, L.C. \& M.D.B. Burt, 1978. Revision of the Turbellarian Genus Ectocotyla (Seriata, Monocelididae) associated with the crabs Chionoecetes opilio and Hyas araneus. J. Fish. Res. Board Can., 35: 1223-1233.

Karling, T.G., 1956. Morphologisch-histologische Untersuchungen an den männlichen Atrialorganen der Kalyptorhynchia (Turbellaria). Ark. Zool., 9: 187-279.

Karling, T.G., 1966. Marine Turbellaria from the Pacific coast of North America. Coelogynoporidae and Monocelididae. Ark. Zool., 18: 493-528.

Levan, A., K. Fredga \& A.A. Sandberg, 1964. Nomenclature for centromeric position on chromosomes. Hereditas, 52: 201-202.

Martens, P.M., 1984. Comparison of three different extraction methods for Turbellaria. Mar. Ecol. Progr. Ser., 14: 229234.

Martens, P.M. \& M. Curini-Galletti, 1987. Karyological study of three Monocelis-species, and description of a new species from the Mediterranean, Monocelis longistyla sp. n. (Monocelididae, Plathelminthes). Microfauna marina, 3: 297-308.

Martens, P.M., M. Curini-Galletti \& I. Puccinelli, 1989a. On the morphology and karyology of the genus Archilopsis (Meixner) (Platyhelminthes, Proseriata). Hydrobiologia, 175: 237-256.

Martens, P.M., M. Curini-Galletti \& P. van Oostveldt, 1989b. Polyploidy in Proseriata (Plathelminthes) and its phylogenetical implications. Evolution, 43: 900-907.

Matthey, R., 1949. Les chromosomes des Vertébrés: 1-344 (Rouge, Lausanne).

Schockaert, E.R. \& P.M. Martens, 1987. Turbellaria from Somalia. IV. The genus Pseudomonocelis Meixner, 1943. Monit. zool. ital. (N. S.), Suppl., 22: 101-115.

Sopott-Ehlers, B., 1993. Ultrastructural features of the pigmented eye spot in Pseudomonocelis agilis (Plathelminthes, Proseriata). Microfauna marina, 8: 77-88.

Received: 12 June 1995

Revised: 15 September 1995 